\title{
An Advanced Protection Scheme for Enabling an LVDC Last Mile Distribution Network
}

\author{
Abdullah A. S. Emhemed and Graeme M. Burt, Member, IEEE
}

\begin{abstract}
Low voltage direct current (LVDC) distribution systems have the potential to support future realization of smart grids and enabling of increased penetration of distributed renewables, electric vehicles, and heat pumps. They do, however, present significant protection challenges that existing schemes based on dc fuses and conventional electro-mechanical circuit breakers cannot manage due to the nature of dc faults and slow device performance. Therefore, this paper presents an advanced protection scheme that addresses the outstanding challenges for protecting an LVDC last mile distribution network. The scheme takes advantage of advanced local measurements and communications that will be naturally integrated in smart grids, and the excellent level of controllability of solid state circuit breakers. It thus provides fast dc fault detection and interruption during dc transient periods, in addition to achieving fault limitation and fast reliable restoration. The introductory part of the paper quantifies the potential benefits of LVDC last mile distribution networks, and discusses the potential LVDC architectures that best utilize the existing plant. Based on the new LVDC architectures, a typical U.K. LV network is energized using dc and modeled, and is used as a case study for investigating the protection issues and evaluating the new protection scheme performance through simulation.
\end{abstract}

Index Terms-Distributed energy resources, low voltage direct current (LVDC) distribution systems, power system protection, smart grid, solid state circuit breakers.

\section{INTRODUCTION}

$\mathbf{H}$ ISTORICALLY, the first distribution power system to supply electricity to customers in a district area (Edison's Pearl Street Station) was introduced in 1882 as low voltage direct current (LVDC) [1]. But ac has dominated since, because it was more manageable to economically transmit ac power over long distances [1]. Currently and because of advances in control and power electronics technologies, dc has been increasingly used particularly for long high voltage dc (HVDC) transmission lines to provide a cost effective solution for transferring power over long distance with better power flow controllability. At distribution levels in today's public power systems, dc networks are not widely used yet, and

Manuscript received August 9, 2013; revised February 23, 2014 and May 13, 2014; accepted June 20, 2014. This work was supported by the Research Councils UK's (RCUKs) Energy Programme as part of the Top \& Tail Transformation programme under Grant EP/I031707/1. Paper no. TSG-00628-2013.

The authors are with the Institute for Energy and Environment, Department of Electrical and Electronic Engineering, University of Strathclyde, Glasgow G1 1XW, U.K. (e-mail: abdullah.emhemed@strath.ac.uk; graeme.burt@strath.ac.uk).

Color versions of one or more of the figures in this paper are available online at http://ieeexplore.ieee.org.

Digital Object Identifier 10.1109/TSG.2014.2335111 their applications are limited to specific areas such as auxiliary installations in power plants and substations, electric traction systems due to the wide usage of dc motors, and for aircraft power systems and electric ships due to the enhanced controllability of dc [2]. Recently, LVDC distribution systems have been considered as one of the efficient energy technologies for powering different sized data centers [3], [4].

With the help of modern power electronics and advanced smart grid technologies, it is believed that LVDC distribution systems have the potential to be a valuable component to meet a number of the challenges that existing last mile distribution electricity networks will face during the transformation to smart grids. The last mile distribution networks expect more connection of small scale renewable and advanced distributed energy resources (DERs) in future in addition to supplying more heat and transport demands [5]. Such changes will cause the future grid's last mile to experience significant pressure for the provision of significantly increased power flow capacity and the accommodation of decentralized controls. Further constraints on the choices made in changing the last mile network stem from the scale and intrusive nature of the LV networkoptions where wholesale changes to cable assets involving significant numbers of disruptive street works can be avoided during the transition of the network are very attractive. There is therefore a need for a rethink of the new standard designs to be adopted in last mile networks. LVDC with the help of smart controls and advanced information and communication technology's (ICTs) have the potential to facilitate this transformation, and offer more advantages over the corresponding LV ac systems [6].

However, the implementation of LVDC systems introduces a new complex arrangement of mixed ac and dc, and this presents significant technical challenges for protecting and operating the new system. For example, under fault conditions, as the system becomes more complex new forms of faults with different fault transients will be introduced and different system responses are anticipated. This is in addition to the problems linked to interrupting a dc fault current without natural zero crossing points compared to ac.

Therefore, the focus of this paper is on the technical protection issues and solutions that enable an LVDC last mile distribution network. The outline of the paper is as follows. Section II quantifies the potential benefits of using dc instead of ac across the LV network last mile. Section III discusses the potential LVDC architectures that best utilize the existing plant. Section IV investigates the outstanding protection challenges of an LVDC network with high penetrations 
of microgeneration, and evaluates the effectiveness of existing protection options for protecting LVDC systems. In Section V, a new protection solution that can provide more resilient and more reliable operation for an LVDC network integrated with high penetrations of microgeneration has been developed, and evaluated through simulation analysis. Finally, the conclusions of the work presented in this paper are drawn in Section VI.

\section{Potential Benefits of LVDC Last Mile}

The European Union (EU) (LVD) 2006/95/EC standard permits the use of higher dc voltages up to $1.5 \mathrm{kV}$ for $\mathrm{LV} \mathrm{dc}$ distribution systems compared to $1 \mathrm{kV}$ for $\mathrm{LV}$ ac systems [7]. This has technical advantage of delivering higher power as will be discussed later. Also in dc systems, the inductances have limited effect on the voltages during normal operation, and thus the reactive current component that introduces more losses is insignificant. In addition, the skin effect that normally increases the cable resistance in ac networks has no impact in dc cables. The advantages of these features in addition to better controllability of dc systems for improving future distribution network operation are discussed as follows.

\section{A. Improving System Efficiency and Increasing Power Flow Capacity}

Using LVDC with higher voltages will reduce the thermal losses and voltage drops in LV cables, and allow a higher power capacity to be obtained and system efficiency to be improved. This is significantly important for rural networks which have long feeders and system efficiency can be an issue. The experience from a real rural LVDC test network as a part of Finnish national smart grids research program has concluded that LVDC is more efficient solution to rural ac networks when the feeders lengths are over $1 \mathrm{~km}$ [8]. LVDC has also the potential to enable increased power flow capacity for urban networks to supply higher load density. Another advantage for urban network examples is reduced fault levels by the converters across the network. This could facilitate more the operation of $\mathrm{LV}$ ring configurations to improve the redundancy level, and allow the use of equipment with lower short circuit rating and reduced cost.

\section{B. Facilitating the Connection of Renewable Energy Resources and DC Loads}

Most of the decentralized devices generate/consume dc or require a dc intermediate stage. These devices can be connected directly or by dc/dc converters to LVDC networks, and the energy losses which is typically $7 \%-15 \%$ for converting dc to ac can be reduced [3]. It is also easier to connect multiple sources in parallel to dc systems than to ac systems, where frequency synchronization is not required. An LVDC network is also more suitable for the connection of large numbers of dc power consuming devices. The need for using large numbers of adapters to convert $230 \mathrm{~V}$ ac to dc can be removed, resulting in reduced losses and saved cost [9]. The transformers used for the adaptors of electronic equipment can cause considerable losses during stand-by mode. As stated in [9], and according to the International Energy Agency (IEA), in the EU, the total domestic consumption of electronic equipment in stand-by mode has been estimated to be more than $36 \mathrm{TWh} / \mathrm{year}$.

\section{Potential Benefits for Electricity Market}

LVDC with advanced ICT systems has the potential to allow customers, suppliers, and operators to benefits from the enhanced controllability and flexibility in operation. This could offer more flexible market mechanism with better stimulation of customers to control their demand, and facilitate their choices in competitive retail market with potential financial benefits to be realized [10].

\section{LVDC Benefits Versus the Cost}

The technical benefits of an LVDC application should be balanced in practice with the cost, where the life-cycle cost and the energy efficiency are the main drivers for the LVDC to take place in future [6]. In general, the lifetime of the electronic conversion devices is normally shorter than traditional transformers. In spite of this issue, LVDC systems have already proven their economic benefits for other existing applications. The recent Electric Power Research Institute (EPRI) research has concluded that using $380 \mathrm{~V} \mathrm{LVDC}$ to supply small and medium sized data centers will improve the electrical efficiency up to $15 \%$ and with $36 \%$ lower lifetime cost [4]. Also, $\mathrm{ABB}$ has reported that the $1 \mathrm{MW} 380 \mathrm{~V}$ dc network built in 2012 to supply a medium sized data center was $10 \%$ less than the ac system in terms of capital costs [4].

\section{Proposed Architecture of LVDC Last Mile}

The example scenario described in this paper considers energizing an existing last mile distribution network using dc to achieve the aforementioned benefits. In such a case, the move to dc should make the best use of existing ac assets and ensure the reliability and integrity of the new system. A number of key issues that are still facing the design of LVDC last mile in terms of new topology, operating voltage levels, and earthing arrangements are discussed as follows.

\section{A. LVDC Last Mile Topology}

Considering a typical U.K. LV configuration as the test network, the new LVDC network will be supplied from the secondary substations 11/0.4 kV Dy11 transformer via ac/dc converter as shown in Fig. 1. In general, an LVDC can be interfaced to the ac grid by fully controlled interfaces such as voltage source converters (VSCs) based on isolated gate bipolar transistor (IGBT) switches. IGBT-based VSCs have the ability to control the dc voltages, and allow independent control of active and reactive power between the LVDC and the ac grid. In terms of dc feeder connections, the existing ac cables can be configured as either unipolar or bipolar when are used for dc [8]. Bipolar systems provide more voltage level options and higher power capacity than unipolar. More details on how to configure the existing ac cables to be used for $\mathrm{dc}$ applications are given in [11]. 


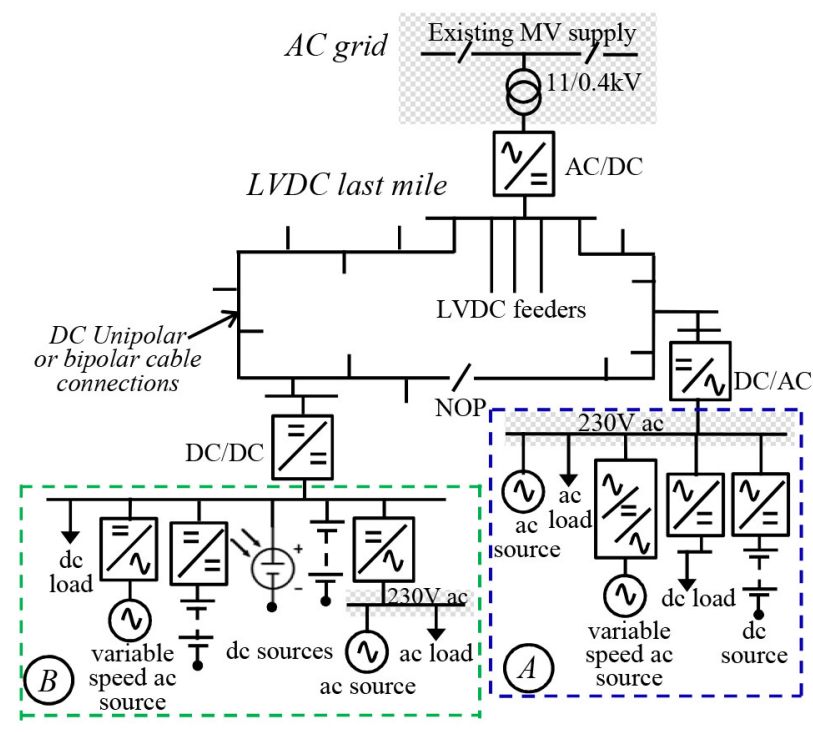

Fig. 1. LVDC last mile distribution network example.

End user interfaces are also an important part that helps LVDC to maximize its benefits. Fig. 1 depicts both connections to a conventional ac-load household and a future dc enabled house, shown as A and B, respectively. The ac house requires a dc/ac inverter to provide $230 \mathrm{~V}$ ac, and all dc loads and sources are interfaced to the host system through dc/ac converters, and high speed ac sources such as microwind and micro gas turbines are interfaced by ac/dc/ac converters. When these devices are connected to the dc enabled house, the conversion stages are reduced. The electronic devices internally powered by dc can be connected directly to the system or through $\mathrm{dc} / \mathrm{dc}$ converters. This is in addition to the possibility of connecting multiple sources in parallel to the dc system as shown for customer B in Fig. 1. Any domestic ac loads such as ac rotating machines can still be supplied by ac/dc converters in the dc enabled house, though they are likely to be few in number in the future.

\section{B. Operating DC Voltage Levels}

With respect to LVDC operating voltages, there is lack of standards due to the lack of applications for such networks. The EU LVD2006/95/EC as mentioned earlier identifies the range of dc low voltages to be from $75 \mathrm{~V}$ up to $1.5 \mathrm{kV}$, with any voltage out of this range considered beyond LV [7]. But there is as yet no agreed nominal value as there is in traditional LVAC distribution systems. The only existing single worldwide standard for an LVDC voltage is the $380 \mathrm{Vdc}$ which has been adopted for powering numbers of data centers [4]. The main driver for choosing this standard is stated to be low capital and operating cost [4], [12]. As for future LVDC last mile networks, the most appropriate operating voltage still remains as an open question.

The rating of existing LV cables can also have an impact on selecting dc operating voltages. The existing LV ac cable ratings are specified as root mean square (RMS) limits, but the applied voltages clearly reach their associated peak values. Thus, if an existing LV cable were to be used for a dc application, the dc voltage rating can be equal to the peak of the ac voltage instead of the ac RMS. Using de voltages equivalent to the ac peaks will deliver the same power with lower current, resulting in reduced thermal losses in LV feeders. A typical $1 \mathrm{kV}$ ac PVC insulated underground cable has been successfully used as a dc feeder with voltages up to $\pm 750 \mathrm{Vdc}$ for the Finnish LVDC test network, and the continuous 5000 $\mathrm{h}$ of operation have not caused any failure or damage to the cable [8]. The only problem with using higher dc voltage is the requirement for converters with higher voltage ratings which may lead to higher cost. The research in [6] has considered the impact of different dc voltages on the life cycle costs of converters and dc cables in LVDC systems, and has found that the most optimal dc voltage lies between 0.6 and $1 \mathrm{kVdc}$. This analysis has based on the existing average cost of power electronic devices. With technology advancement and increased application of dc, the cost of these devices will reduce. This may allow the optimal voltages to increase further, by which further capacity will be provided. To sum up, there is an urgent need for standards organizations to provide a nominal dc voltage that will maximize the value of the application of $\mathrm{dc}$ technologies in public distribution systems.

\section{Earthing Arrangements}

The earthing system of an LVDC network can be a complex issue, and different earthing systems result in different voltage control and protection performance. The LVDC network can be operated as an unearthed IT-system with no short-circuit path between the ac and dc systems through the earth, and the consumers' networks can be locally earthed. This option provides an additional protection to the converters against high earth fault currents. However, additional protection such as residual current devices (RCD) will be necessary to protect against earth faults on the consumers' side of unearthed LVDC systems [13]. Within unearthed LVDC, it will be more difficult to keep the neutral current to zero for balancing the poles' voltages in bipolar systems. So, bipolar LVDC networks may require solid earth at the neutral, or earthing through resistances to minimize earth fault currents and balancing the voltages. Another issue is that, existing regulations such as electricity safety, quality, and continuity regulations (ESQCR) do not allow unearthed IT-system configuration for LV public networks in the U.K. [14]. This may lead to the need for existing regulations to be revised in order to allow more flexible earthing arrangements for public LVDC, while still ensuring the safety of personnel and equipment.

\section{LVDC Last Mile Protection Issues}

Protection systems' effectiveness is crucial in future LVDC development. This is because the change to dc creates new forms of faults with different natures and different transient compared to ac. Previous research [15] has shown that for a de fault at the converter terminals, a high transient shortcircuit up to 35 times the steady-state fault current can flow within less than $4 \mathrm{~ms}$. Such high current amplitudes will flow through the network sensitive components with a significant $I^{2} t$ thermal energy, resulting in the requirement for more expensive plant with higher ratings. Another issue is the 


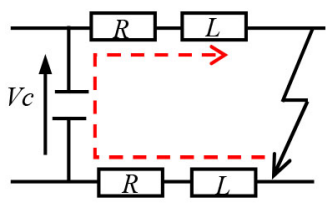

(a) (b)

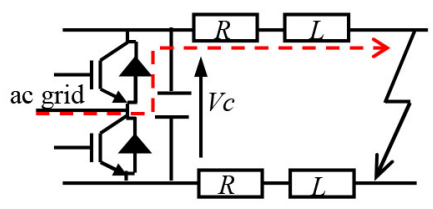

Fig. 2. Equivalent circuit of faulted dc feeder. (a) Capacitor discharge current contribution. (b) Anti-parallel diodes fault current contribution.

lack of representative dc protection standards for accurately characterizing de short circuits during both the transient and steady state periods. IEC61660 is the most inclusive standard that has been widely used for characterizing faulted dc auxiliary systems [16]. However, the research in [15] has shown that IEC61660 underestimates the dc transient phenomena of faulted last mile networks. Therefore, more accurate mathematical models of dc faults for designing more effective dc protection are discussed next, followed by the issues of using existing protection against dc faults.

\section{A. Characteristics of DC Short-Circuit Currents}

When a dc fault is initiated, the IGBT switches of the converters are normally blocked for self-protection and the smoothing capacitor of the filters as shown in Fig. 2(a) will immediately act as a significant dc source, and feed a high transient current decaying exponentially as given in (1) until the capacitor voltage given in (2) becomes zero [17]

$$
\begin{aligned}
i_{C} & =C \frac{d V_{c}}{d t}=-\frac{I_{0} \omega_{0}}{\omega} e^{-\delta t} \sin (\omega t-\beta)+\frac{V_{0}}{\omega L} e^{-\delta t} \sin \omega t \\
V_{C} & =\frac{V_{0} \omega_{0}}{\omega} e^{-\delta t} \sin (\omega t+\beta)-\frac{I_{0}}{\omega C} e^{-\delta t} \sin \omega t .
\end{aligned}
$$

Here, $V_{C}$ and $i_{C}$ are the voltage across the capacitor and the discharge current of the capacitor, respectively. $V_{0}$ and $I_{0}$ are the initial voltage and current of the smoothing capacitor. $C$ is the capacitance value, $\delta=R / 2 L$, and $\omega_{0}=\sqrt{\delta^{2}+\omega^{2}}$. $\mathrm{R}$ and $\mathrm{L}$ are the equivalent resistance and inductance from the fault point to the dc source. Also,

$$
\begin{aligned}
\omega & =\sqrt{(1 / L C)-(R / 2 L)^{2}} \\
\beta & =\arctan (\omega / \delta) .
\end{aligned}
$$

The time for the capacitor voltage to drop to zero is given by

$$
t_{1}=t_{0}+(\pi-\gamma) / \omega
$$

$t_{0}$ is the initial time when the fault is initiated, and

$$
\gamma=\arctan \left[(\sin \beta) /\left(\cos \beta-\left(I_{0} / V_{0} \omega_{0} C\right)\right)\right] .
$$

When the capacitor is completely discharged, the antiparallel diodes as shown in Fig. 2(b) will be forward biased, and act as a bridge rectifier and continue supplying the fault during the transient. The fault current of the dc feeder inductors will be circulated in the diodes, and it can be calculated from the following equation [17]:

$$
i_{L}=I_{0}^{\prime} e^{-(R / L) t}
$$

where $I_{0}^{\prime}$ is the initial current value of the inductor.
After the transient is passed, a steady state dc fault current will be supplied by the grid through the antiparallel diodes. Each leg of the converter will pass one phase current as given in

$$
\begin{aligned}
i_{g a}= & I_{m} \sin \left(\omega_{s} t+\alpha-\varphi\right)+\left(i_{m 0} \sin \left(\alpha-\varphi_{0}\right)\right. \\
& -I_{m} \sin (\alpha-\varphi) e^{-t / \tau}
\end{aligned}
$$

where $\omega s$ is the synchronous angular frequency, $\alpha$ is the phase A voltage angle, and

$$
\phi=\tan ^{-1}\left(\omega_{s}\left(L_{g}+L\right) / R\right) .
$$

The time constant $\tau=(L g+L) / R$. Im is the grid current magnitude, and $I_{m 0}$ and $\varphi_{0}$ are the initial grid current amplitude and initial phase angle, and $L_{g}$ is the grid inductance. The total current contribution to the dc steady-state fault current supplied by the grid is the sum of the three phases a, b, and c currents $i_{g a}, i_{g b}$, and $i_{g c}$.

\section{B. Issues With Existing DC Protection Options}

Interrupting dc fault current with the same features as described above is more difficult than for ac. Three existing protection methods against dc faults are discussed here, and evaluated. The first method is protecting dc systems from the ac side by measuring de voltage and current during the fault and operating the breakers on the ac side. Such a solution is widely used as an economic way to protect dc lines in HVDC systems [18], but will disconnect the complete dc network. The selectivity of such a solution can be improved by using the handshaking protection method as developed in [19]. The method uses ac breakers on the ac system and fast acting mechanical switches on the dc system. The switches do not break any dc faults, and are used only for reconfiguring $\mathrm{dc}$ lines after the fault is cleared by the ac breakers. Such a protection option could be effective for HVDC but not the best option for local distribution networks. This is because the entire network is temporarily disconnected until the mechanical switches perform their functions, and this can lead to power quality and local stability issues.

The second dc protection option is by creating zero crossing points for dc fault currents. This is achieved by using a series reactor with conventional electro-mechanical circuit breakers (EMCBs) on the dc side [20]. The reactor is used to limit the fault magnitude, cause the dc fault current to oscillate, thus creating a zero crossing, with the EMCB interrupts the fault at the first zero crossing. Such a method is less reliable for high impedance faults, where a relatively large reactor is required to create oscillation. In addition, adding more reactance will lead to more fault stress due to the release of larger stored energy during the fault.

The third dc protection method is by directly interrupting the dc fault on the dc side by devices that do not require zero crossing points such as current-limiting fuses and EMCBs such as moulded case circuit breakers (MCCBs) [21]. However, the performance of such devices for dc protection is slower than for ac. Extinguishing the dc arc is more difficult than for ac, where increased arc length and arc splitter are required [22]. The dc fuses and MCCBs performance for protecting a simple LVDC distribution network has been tested in [13]. The 
short-circuit fault at the ac end user was cleared within $0.04 \mathrm{~s}$ by MCCB on the consumer side, and the fault on the dc side of the unearthed LVDC example required $5.1 \mathrm{~s}$ to be cleared by an insulation monitoring relay on the dc side and a breaker on the ac side. Such slow operating times cannot protect the system from the high peaks of dc faults during the transient, and the following fault consequences are expected.

1) Converters and other sensitive devices become defenseless against high transient dc faults during the discharge of the filters' capacitors, resulting in absorbing high thermal energy for longer time and increasing the requirements for higher current ratings.

2) The rapid depression of dc voltages as a result of high transient currents will last longer. This will make the converters lose control and more likely trip before downstream protection, leading to substandard protection selectivity and unnecessary disconnection.

3) Post-fault high transient spikes of dc voltages are expected. The research in [21] has proven that when a dc fault on an LV side was cleared after $5 \mathrm{~ms}$, a large transient dc voltage enough to impact the unfaulted feeders' loads was experienced.

4) It will be more difficult to maintain the stability of local microgenerators and avoid sympathetic tripping against remote dc faults due to the sensitivity of these devices to undervoltage conditions during the dc transient.

Subsequently, to avoid the above-listed operation issues, dc faults need to be cleared during the transient period within timescale no more than $4 \mathrm{~ms}$ [15]. This requires very fast dc fault detection and interruption with a good level of selectivity. Such protection performance within such a timescale cannot be achieved by using traditional dc fuse-based and EMCB-based protection schemes. Therefore, the next section develops a new protection solution to address these issues.

\section{FAst Acting LVDC Protection Scheme}

An advanced protection scheme that performs fast and selective dc protection for new LVDC last mile distribution networks is developed in this section. The scheme overview is described next, followed by an evaluation of its effectiveness through modeling and simulation studies.

\section{A. Overview of the Scheme}

The new protection solution is communication-based with a combination of ac and fast acting electronic-based $\mathrm{dc}$ protection. It is based on the measurement of dc fault current directions and magnitudes, and dc voltages during dc fault transient periods using multiple intelligent electronic devices (IEDs) that have self-monitoring, control, and communication functions. Solid state circuit breakers (SSCBs) which can be turned on and off within few microseconds are used for interrupting dc faults. The common controllable examples of SSCBs that can be used for dc protection are; the normally-on Silicon carbide junction field effect transistor (SiC JFET), an integrated gate-commutated thyristor (IGCT), and an IGBT. SiC JFET and IGBT-based SSCBs have relatively faster switching speed than the IGCT, but the IGCT is

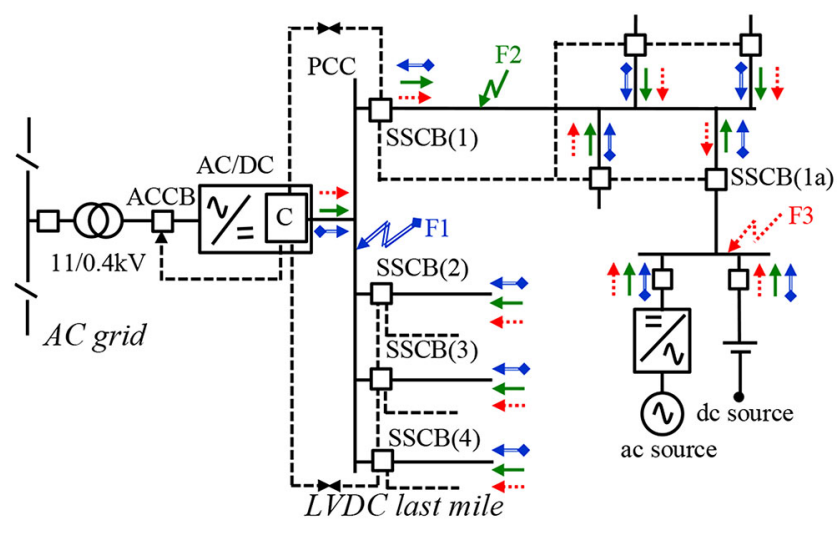

Fig. 3. LVDC network protected by fast acting protection scheme.

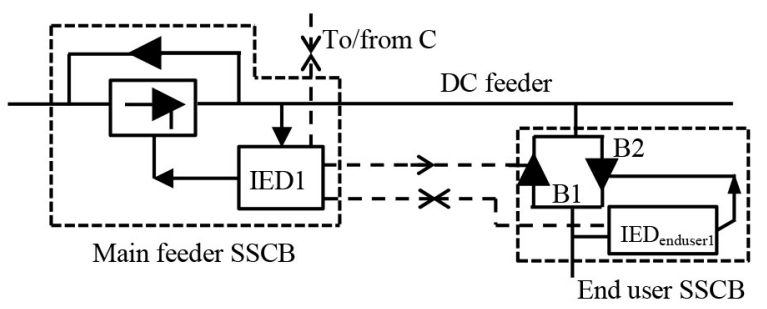

Fig. 4. Structure of the dc feeder's protection and selected end user protection.

still 900 times faster than a typical EMCB [23]. Any type of these SSCBs can be used within the developed protection scheme, but the IGCT has lower on-state losses than the IGBT and higher current rating capabilities than SiC JFET which requires many devices to be paralleled. Therefore, IGCT SSCB is considered in the developed scheme.

Fig. 3 redraws the test network of Fig. 1 for clarity, and is used to explain the scheme principles. The ac breaker shown as ACCB in Fig. 3 is used to protect against internal faults of the main converter and external faults on the dc point of common coupling (PCC). The ACCB is controlled by an intelligent electronic device (IED) relay which can be equipped within the main converter, shown as $\mathrm{C}$ in Fig. 3. On the dc side, each main dc feeder is protected by one SSCB as shown in Fig. 3, and controlled by a local IED relay. Fig. 4 depicts in more detail the structure of the first dc feeder's protection and selected end user protection. The SSCB of the end user has two antiparallel controlled switches. One switch shown as B1 in Fig. 4 is remotely controlled by the IED located at the beginning of main feeder (IED1) in order to block reverse fault currents supplied by microgenerators, and facilitate controllable reclosing. With such a design there is no need for having a reverse controllable switch at the beginning of the feeder to block reverse fault currents, and the breaker can be protected by anti-parallel diodes in case of upstream faults. The other end user antiparallel switch shown as B2 in Fig. 4 is locally controlled by

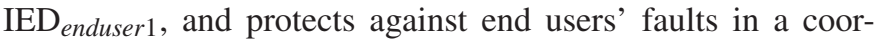
dinated way with the upstream protection. The coordination between IED1 and IED enduser $1_{1}$ is achieved by setting the pick up current of IED $_{\text {enduser } 1}$ lower than the pick up of IED1.

When a dc fault occurs on the dc side, all the network devices will notice the disturbance in different ways. Changes in the current magnitudes and directions in addition to the 


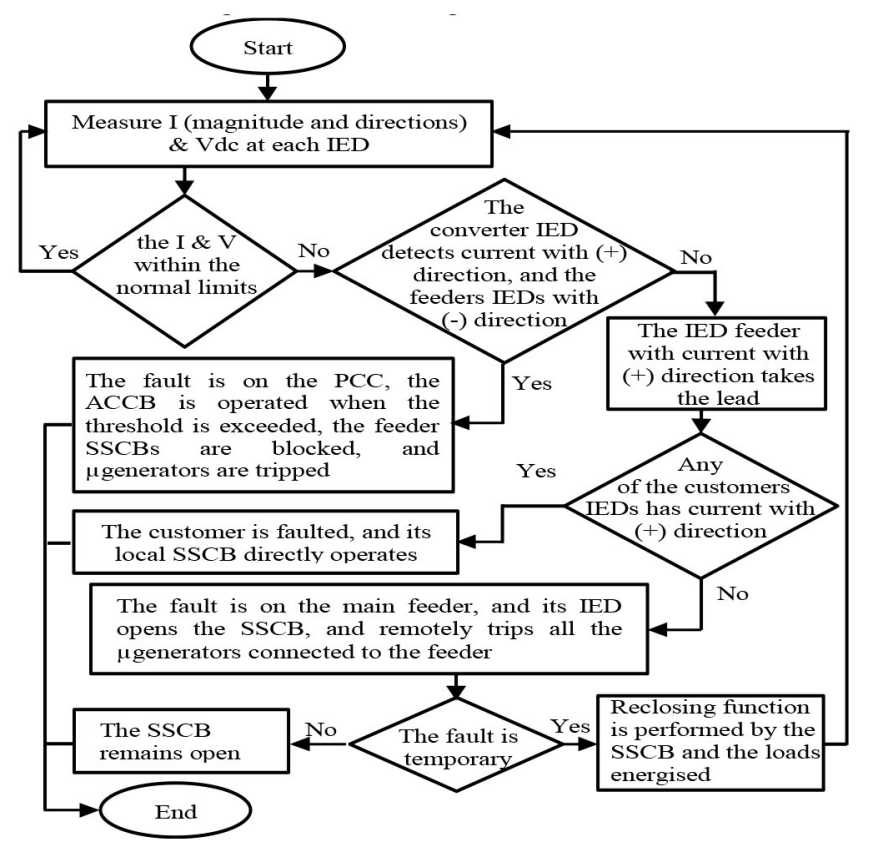

Fig. 5. Algorithm of the developed dc multifunction protection scheme.

rapid decrease in the dc voltages during the fault are used as an indicator for detecting and locating faults, and performing fast selective tripping. The direction of fault currents helps in identifying the fault locations very quickly. The proposed scheme assumes that the direction of currents flow toward the downstream is positive and represented by 1 , and toward the upstream is negative and represented by 0 . Based on these directions and fault current magnitudes, the appropriate relay signals such as a trip signal, a blocking signal, or a reclosing signal to perform the required protection functions and algorithm are provided by the associated IED. The protection functions are described in more detail in Fig. 5. The IEDs exchange the signals only when the dc undervoltage thresholds are exceeded, and send trip signals only when the current thresholds are exceeded. Three fault scenarios associated with fault locations F1, F2, and F3 in Fig. 3 are considered to explain how fast fault detection and selective tripping described in Fig. 5 can be achieved.

When fault F1 as shown in Fig. 3 is considered, the fault will be supplied by the ac grid and the downstream microgenerators. The fault current flows through the relay C (see Fig. 3) will have positive direction 1 , and the reverse currents flow through all the relays IED1-4 and other downstream end users IEDs will have negative direction 0 . Therefore, the available direction-based current information for the relay $\mathrm{C}$ is

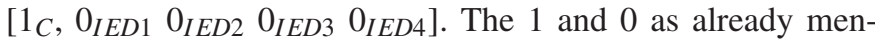
tioned representing the forward and reverse current directions, and the associated relays to these directions are represented by the subscripts. The fault location is then easily identified, as between the IEDs with two opposite directions 1 and 0 (i.e., on the PCC), and when the threshold fault currents are exceeded the following actions are taken.

1) Relay $C$ trips the breaker on the ac side to interrupt the ac grid fault contribution at the first zero crossing.
TABLE I

Converter and Main FeEder Relays Performance DURING FAULT F1

\begin{tabular}{l|l|c|c|c|c|c}
\hline \multirow{2}{*}{$\begin{array}{l}\text { Protection } \\
\text { functions }\end{array}$} & Relays & C & IED1 & IED2 & IED3 & IED4 \\
\cline { 2 - 7 } & Current directions & 1 & 0 & 0 & 0 & 0 \\
\hline Trip function & $\checkmark$ & - & - & - & - \\
\hline Blocking reverse current & - & $\checkmark$ & $\checkmark$ & $\checkmark$ & $\checkmark$ \\
\hline Reclosing function & - & - & - & - & - \\
\hline
\end{tabular}

TABLE II

Converter and Main FeEder Relays Performance DURING FAULT F2

\begin{tabular}{l|l|c|c|c|c|c}
\hline Protection & Relays & C & IED1 & IED2 & IED3 & IED4 \\
\cline { 2 - 7 } functions & Current directions & 1 & 1 & 0 & 0 & 0 \\
\hline \multicolumn{2}{l}{ Trip function } & - & $\checkmark$ & - & - & - \\
\hline Blocking reverse current & - & $\checkmark$ & $\checkmark$ & $\checkmark$ & $\checkmark$ \\
\hline Reclosing function & - & $\checkmark$ & - & - & - \\
\hline
\end{tabular}

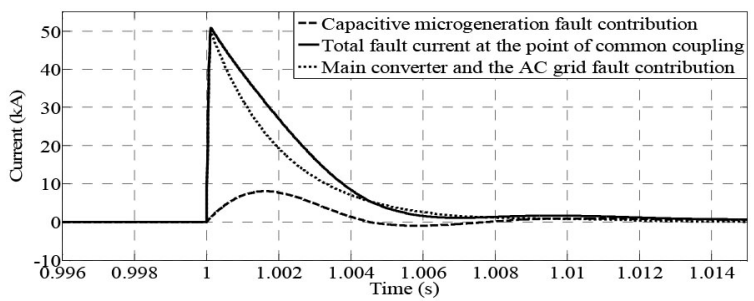

Fig. 6. Transient discharge pole-pole dc fault behavior at the PCC.

2) IEDs1-4 of the main feeders remotely block the microgenerators reverse currents.

Blocking the reverse fault current will reduce the thermal stress on the system during the transient period, and remove the limitations on more renewables uptake due to fault level issues. Table I below explains different protection functions required from different relays for the fault F1 at the PCC.

In the case of fault F2 (see Fig. 3), the fault current direction information seen by relay C, IEDs1-4 are

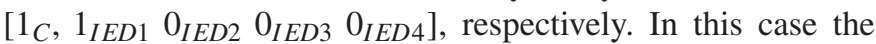
feeder with a current has direction 1 is the faulted feeder, and its relay (IED1) takes the lead. Now looking from the IED1 toward the downstream end users IEDs, the available direction signals for the IED 1 are $\left[1_{\text {IED } 1}, 0_{\text {IEDenduser } 1}\right.$ $\left.0_{\text {IEDenduser } 2 \ldots} \ldots 0_{\text {IEDenduser } N}\right]$ seen by the feeder IED1 and provided by the downstream end users IEDs. The fault is then located on the main feeder, and the following actions as listed in Table II are performed.

1) IED1 remotely trips all the downstream microgenerators.

2) IED1 clears the fault locally by operating its SSCB (1).

3) Taking the advantage of an automatic reset of the SSCB, a controllable reclosing action against temporary faults can be automatically implemented by the IED1.

With respect to the downstream fault F3 as shown in Fig. 3, the fault current directions seen by relay $\mathrm{C}$, the main feeders IEDs, and by the end users IEDs are $\left[1_{C}, 1_{\text {IED } 1} 0_{\text {IED2 }} 0_{\text {IED } 3}\right.$ $\left.0_{\text {IED } 4}, 1_{\text {IEDenduser } 1} 0_{\text {IEDenduser } 2 \ldots} \ldots 0_{\text {IEDenduser } N}\right]$, respectively. The end user with a current with direction 1 is faulted. In this case the fault is local, and can be directly detected by the local $\mathrm{IED}_{\text {enduser } 1}$ and cleared by the associated $\operatorname{SSCB}(1 \mathrm{a})$ without the need for communicating upstream protection. 


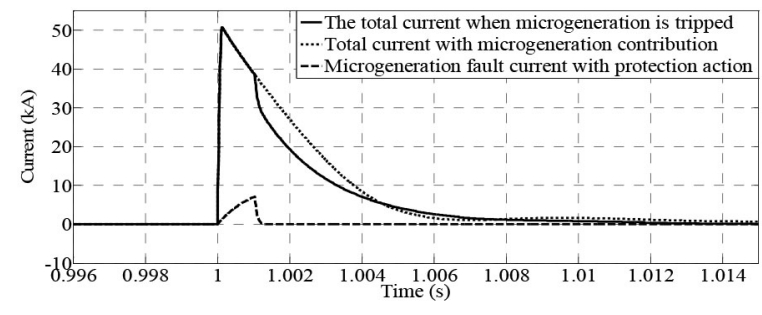

Fig. 7. Transient discharge pole-pole dc fault at the PCC with and without microgeneration contribution.

\section{B. Test Network Modeling}

The LVDC test network described earlier is modeled using PSCAD/EMTDC, and used to demonstrate the developed scheme through simulation. The data of the MV network is based on actual data provided by a U.K. network operator [24]. The MV system is modeled using an ideal voltage source and impedance with $\mathrm{X} / \mathrm{R}=5$ to provide a fault level of $156 \mathrm{MVA}$ at the ring main unit (RMU). An impedance of $4.5 \%$ and rating of 0.5 MVA has been taken for the secondary substation transformer $(11 / 0.433 \mathrm{kV})$. The LVDC network is assumed to be a radial unearthed unipolar network providing $612 \mathrm{~V}_{d c}$ between the two poles, and supplying $400 \mathrm{kVA}$ load. The parameters of the LV cables are $\mathrm{R}_{d c}=0.164 \Omega / \mathrm{km}$, and $\mathrm{L}=0.24 \mathrm{mH} / \mathrm{km}$, and the cables length is assumed to be $1 \mathrm{~km}$.

As aforementioned in Section IV-A, when a dc fault is first initiated the converter IGBTs are immediately blocked, and the fault is supplied by the smoothing capacitor during the transient and by the ac grid through the antiparallel diodes during the steady-state period. So the converter IGBTs are inoperative during the short-circuit, and the converter behaves as a six pulse bridge rectifier with smoothing capacitor. Therefore, the interface of the test LVDC to the ac grid is modeled as a six pulse rectifier with smoothing capacitor $\mathrm{C}=6750 \mu \mathrm{F}$. Such a model is valid for protection studies, and gives the worst dc fault scenario where no converter control action is implemented, and the highest dc short circuit is obtained. The represented studies have also considered the extreme microgeneration fault contribution scenario (100\% of the load supplied locally). The microgenerators are represented by dc current sources connected in parallel with capacitors with $\mathrm{C}=470 \mu \mathrm{F}$. In terms of protection model, the SSCBs are modeled as a typical power electronic switch connected in parallel with a snubber RC circuit, and has a minimum extinction time $=30 \mu \mathrm{s}$. The pickup current of each relay is set as twice of the full load current, and the undervoltage threshold is set to be $85 \%$ of the nominal $\mathrm{V}_{d c}$. A fixed communication delay equals to $1 \mathrm{~ms}$ is applied.

\section{Simulation Studies}

Faults F1, F2, and F3 shown on Fig. 3 are again considered during the simulation analysis. The fault F1 is applied at the $\mathrm{PCC}$, and F2 and F3 are applied on the main feeder and on the end user side, respectively. Fault F1 at the PCC creates a very high transient dc fault current, and its peak $(50 \mathrm{kA})$ is reached within less than $1 \mathrm{~ms}$ as shown in Fig. 6. The discharge of the filters' capacitors of the microgenerators contributes to almost $16 \%$ of the total peak as shown in Fig. 6 with slower rise time due to the dc feeders resistance and inductance. The fault is

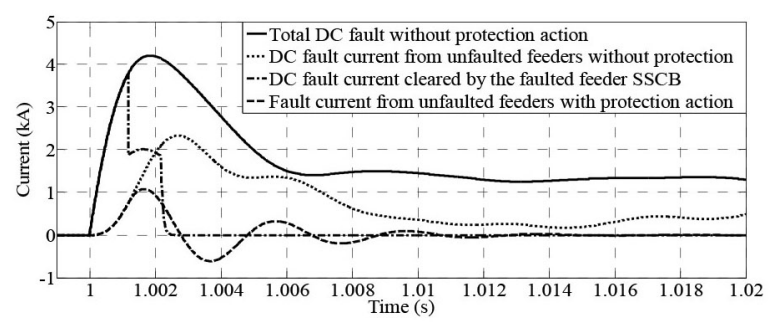

Fig. 8. Comparison between uninterrupted dc discharge fault current and interrupted fault current by SSCB.

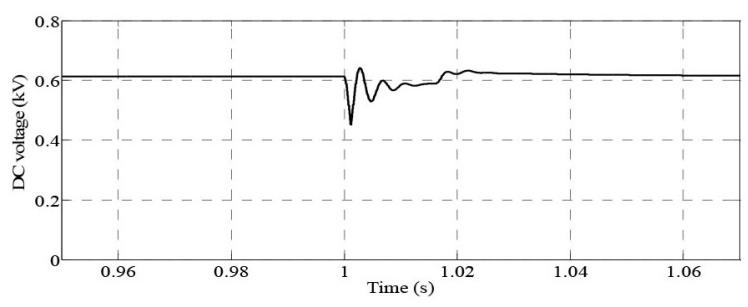

Fig. 9. Impact of reclosing with dead time $15 \mathrm{~ms}$ on the LVDC voltage.

quickly detected by relay $\mathrm{C}$ and cleared from the ac side by the ACCB at the first zero crossing point within $13.2 \mathrm{~ms}$. Such a protection operating time has allowed the passage of the discharge current, but the fast trip of the local generators by downstream SSCBs has reduced the impact of this current during the transient period by reducing the decay time as shown in Fig. 7. The results have shown that local microgenerators can be disconnected remotely within $30 \mu$ s plus $1 \mathrm{~ms}$ communication delay.

When fault F2 is applied, the protection scheme has shown a good level of discrimination - the relay $\mathrm{C}$ detects the fault but does not react. After $1 \mathrm{~ms}$ communication delay (the feeder IED to communicate with the end users' IEDs), the fault F2 is quickly cleared by the relay and the SSCB of the faulted feeder, and by disconnecting the downstream microgenerators within $2 \mathrm{~ms}$ (including the impact of two-way communication) as shown in Fig. 8. Such fast fault interruption during the transient period has protected the last mile from being exposed to high current with $5 \mathrm{kA}$ peak for longer period as illustrated in Fig. 8. This is in addition to significantly limiting the fault contribution from the microgenerators of the unfaulted adjacent feeders as shown in Fig. 8. The results have also proven that the disconnected loads can be automatically reconnected by the controllable reclosing function of the feeder SSCB (1). The impact on the dc voltage during the fault interruption and reclosing is very limited as given in Fig. 9. This will improve the ride through capability of the healthy feeders' microgenerators. As for the fault F3, the fault is cleared locally by the end user SSCB(1a) within $30 \mu$ s as shown in Fig. 10. These results have also ensured selectivity between the end user $\operatorname{SSCB}(1 \mathrm{a})$ and the feeder SSCB (2).

It can be concluded from the simulation studies that in addition to the provision of fast dc fault detection and interruption which prevent dc faults from reaching damaging levels, more elaborate protection functions such as fault limitation and, fast reliable restoration have also been achieved. Within the studies the impact of high frequency noise currents on the sensitivity 


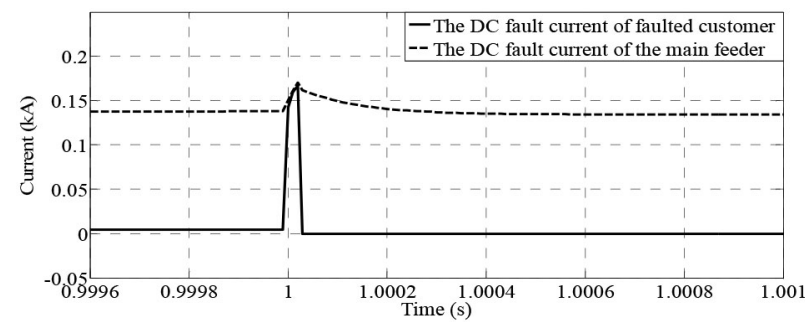

Fig. 10. Downstream dc fault cleared by the end user SSCB.

of the SSCBs is assumed to be negligible. This phenomenon will be considered in future work in order to evaluate the reliability of the developed SSCB-based protection scheme and avoid unpredictable protection behavior. In addition, to justify the implementation of the developed scheme, the added onstate losses of SSCB and increased cost need to be balanced with the afforded benefits.

\section{CONCLUSION}

This paper has presented a new protection solution which provides the fast and selective tripping required of new LVDC last mile distribution networks. The provision of this solution will thereby enable the potential benefits afforded by energizing last mile using dc. The benefits include accommodating increased penetration of distributed renewables, supporting better control, supplying new heat and transport demands, and reducing losses in LV feeders. A representative architecture was created, and test network modeled, in order to evaluate the new protection scheme's effectiveness in simulation. Results show that more resilient network performance can be delivered by quickly detecting and interrupting dc faults during transient periods at low current levels and within small timescales. This has significantly limited the fault level, and supported the ride through capability of local generation. In addition, the system reliability has been improved by implementing controllable reclosing functions and reducing restoration times.

\section{REFERENCES}

[1] IEEE Global History Network. (2013, Jun. 28). Milestones: Pearl Street Station [Online]. Available: http://www.ieeeghn.org/wiki/index.php/ Milestones:Pearl_Street_Station

[2] IEEE Standard for DC Traction Power System Field Testing and Acceptance Criteria for System Applications up to $1500 \mathrm{~V}$ DC Nominal, IEEE Standard 1653.4-2011, Oct. 2011.

[3] B. T. Patterson, "DC, come home," IEEE Power Energy Mag., vol. 10, no. 6, pp. 60-69, Nov./Dec. 2012.

[4] G. AlLee and W. Tschudi, "Edison redux: $380 \mathrm{Vdc}$ brings reliability and efficiency to sustainable data centers," IEEE Power Energy Mag., vol. 10, no. 6, pp. 50-59, Nov./Dec. 2012.

[5] C. J. Mozina, "Impact of smart grids and green power generation on distribution systems," IEEE Trans. Ind. Appl., vol. 49, no. 3, pp. 1079-1090, May/Jun. 2013.

[6] T. Kiapia et al., "A system engineering approach to low voltage DC distribution," in Proc. Int. Conf. Exhib. Electr. Distrib. (CIRED), Stockholm, Sweden, Jun. 2013, pp. 1-4.

[7] Low Voltage Directive (LVD), EU LV Legislation LVD2006/95/EC, Dec. 2006.

[8] P. Nuutinen et al., "Experiences from use of an LVDC system in public electricity distribution," in Proc. Int. Conf. Exhib. Electr. Distrib. (CIRED), Jun. 2013, pp. 1-4.

[9] D. Nilsson and A. Sannino, "Efficiency analysis of low- and mediumvoltage DC distribution systems," in Proc. IEEE Power Eng. Soc. Gen. Meet., vol. 2. Denver, CO, USA, Jun. 2004, pp. 2315-2321.
[10] (2014, May). Sola Bristol Project Report [Online]. Available: http://www.westernpowerinnovation.co.uk

[11] D. Salomonsson and A. Sannino, "Low-voltage DC distribution system for commercial power systems with sensitive electronic loads," IEEE Trans. Power Del., vol. 22, no. 3, pp. 1620-1626, Jul. 2007.

[12] K. Hirose, "DC powered data centres in the world," presented at the IEC SMB Strategic Group 4 LVDC Workshop, Dresden, Germany, Sep. 2011.

[13] P. Salonen, P. Nuutinen, P. Peltoniemi, and J. Partanen, "LVDC distribution system protection-Solutions, implementation and measurements," in Proc. 13th Eur. Conf. Power Electr. Appl., Barcelona, Spain, Sep. 2009, pp. 1-10.

[14] "Guidance on the electricity safety, quality and continuity regulations 2002," Dept. Trade Ind., London, U.K., Publication Reference URN02/1544, Oct. 2002

[15] A. Emhemed and G. Burt, "The effectiveness of using IEC61660 for characterising short-circuit currents of future low voltage DC distribution networks," in Proc. Int. Conf. Exhib. Electr. Distrib. (CIRED), Stockholm, Sweden, Jun. 2013, pp. 1-4.

[16] Short-Circuit Currents in DC Auxiliary Installations in Power Plants and Substations, IEC61660-1, 1997.

[17] J. Yang, J. E. Fletcher, and J. O'Reilly, "Multiterminal DC wind farm collection grid internal fault analysis and protection design," IEEE Trans. Power Del., vol. 25, no. 4, pp. 2308-2318, Oct. 2010.

[18] J. Candelaria and J. Park, "VSC-HVDC system protection: A review of current methods," in Proc. IEEE/PES Power Syst. Conf. Expo. (PSCE), Mar. 2011, pp. 1-7.

[19] L. Tang and B.-T. Ooi, "Locating and isolating DC faults in multiterminal DC systems," IEEE Trans. Power Del., vol. 22, no. 3, pp. 1877-1884, Jul. 2007.

[20] S. Kulkarni and S. Santoso, "Interrupting short-circuit direct current using an AC circuit breaker in series with a reactor," Adv. Power Electron., vol. 2012, article ID 805958, Aug. 2012.

[21] D. Salomonsson, L. Soder, and A. Sannino, "Protection of low-voltage DC microgrids," IEEE Trans. Power Del., vol. 24, no. 3, pp. 1045-1053, Jul. 2009.

[22] G. D. Gregory, "Applying low-voltage circuit breakers in direct current," IEEE Trans. Ind. Appl., vol. 31, no. 4, pp. 650-657, Jul./Aug. 1995.

[23] R. Schmerda, S. Krstic, E. Wellner, and A. Bendre, "IGCTs vs. IGBTs for circuit breakers in advanced ship electrical systems," in Proc. IEEE Electron. Ship Technol. Symp. (ESTS), Apr. 2009, pp. 400-405.

[24] ScottichPower (SP) Distribution Ltd., Transmission \& Distribution Long Term Development Statement for Year 2012-17, Glasgow, U.K., Nov. 2012.

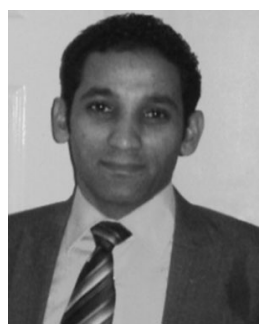

Abdullah A. S. Emhemed received the B.Eng. degree in electrical power systems from Nasser University, Bani-Waleed, Libya, in 2000; the M.Sc. degree in electrical power systems from the University of Bath, Bath, U.K., in 2005; and the $\mathrm{Ph} . \mathrm{D}$. degree in electronic and electrical engineering from the University of Strathclyde, Glasgow, U.K., in 2010

He was with General Electrical Company of Libya, Tripoli, Libya, from 2000 to 2003 . He is currently a Researcher with the Institute for Energy and Environment, University of Strathclyde. His research interests include power system protection and dynamics.

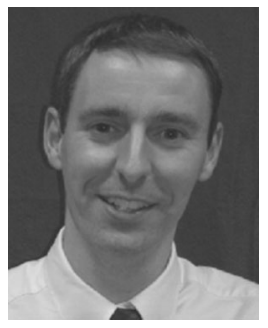

Graeme M. Burt (M'95) received the B.Eng. degree in electrical and electronic engineering and the Ph.D. degree from the University of Strathclyde, Glashow, U.K., in 1988 and 1992, respectively.

$\mathrm{He}$ is currently a Professor of Electrical Power Systems with the Department of Electronic and Electrical Engineering, University of Strathclyde. He is also the Director of the Rolls-Royce University Technology Centre in Electrical Power Systems, and also directs the U.K. Research Council's Sustainable Power Generation and Supply (SUPERGEN) "Highly Distributed Energy Future" Consortium. His international activities include serving on the board of the Association of European Distributed Energy Resources Laboratories (DERlab e.V.), and collaborating in European Union programmes including DERLab, Distributed Energy Resources Research Infrastructure (DERRI), and the European Energy Research Alliance (EERA) in Smart Grids. 